\title{
Predictors of Institutionalization of Dementia Patients in Mild and Moderate Stages: A 4-Year Prospective Analysis
}

\author{
Kathrin Eska ${ }^{a} \quad$ Elmar Graessel $^{a} \quad$ Carolin Donath $^{a} \quad$ Larissa Schwarzkopf $^{b}$ \\ Joerg Lauterberg ${ }^{c}$ Rolf Holle \\ ${ }^{a}$ Center of Health Services Research in Medicine, Department of Psychiatry and \\ Psychotherapy, Friedrich-Alexander Universitaet Erlangen-Nuernberg, Erlangen, \\ ${ }^{b}$ German Research Center of Environmental Health, Institute of Health Economics and \\ Health Care Management, Helmholtz Zentrum Muenchen, Munich, and ${ }^{\mathrm{C}}$ Institute for \\ Quality and Efficiency in Health Care (IQWiG), Cologne, Germany
}

Key Words

Age $\cdot$ Caregivers $\cdot$ Community health services $\cdot$ Nursing homes $\cdot$ Cost of illness $\cdot$ Home nursing · Proportional hazard models · Primary health care · Long-term care · Models, theoretical

\begin{abstract}
Background: Institutionalization is the most important milestone in the care of dementia patients. This study was aimed at identifying relevant predictors of institutionalization in a broad empirical context and interpreting them on the basis of the predictor model proposed by Luppa et al. [Dement Geriatr Cogn Disord 2008;26:65-78]. Methods: At the start of this study, 357 patients with mild to moderate dementia were examined by their general practitioners, and a telephone interview was conducted with their caregivers. Four years later, the outcomes 'institutionalization' and 'death' were determined from health insurance data. Forty-one variables were examined for their predictive influence by univariate and multivariate Cox regression. Results: The risk of institutionalization increased significantly $(p \leq 0.05)$ with older ages of patients [hazard ratio $(H R)=1.05$ ] and caregivers $(H R=1.03)$, a higher educational level of the caregiver ( $H R=1.83)$, greater use of community health services ( $H R=1.59)$, greater caregiver burden ( $H R=1.02)$, and when the caregiver and patient lived apart $(H R=1.97)$. Conclusion: The results show that there is a multifactorial influence on institutionalization of dementia patients by sociodemographic, health-related, and psychological aspects as well as the care situation, thus validating the predictor model by Luppa et al. [Dement Geriatr Cogn Disord 2008;26:65-78]. Caregiver burden was found to be the strongest predictor accessible to interventions.




\section{Introduction}

Institutionalization from an elderly person's point of view often means the loss of their lovely long-term home and their familiar social environment, and the abandonment of memories, identity, independence, autonomy, and dignity. Institutionalization can indeed be considered a 'critical life event', which has varied effects on everyday life and requires the behavioral, cognitive, and emotional reorientation and the adaptation of all persons involved. Often, older patients in advanced stages of dementia are transferred from being cared for at home to long-term care in a nursing home [1], i.e. they are institutionalized, because the care of elderly patients with chronic progressive diseases is a great challenge for their caregivers and families. On the one hand, for the dementia patient, institutionalization may actually have positive effects, such as the improvement of physical symptoms and functional level [2-4]. On the other hand, institutionalization also has the bad reputation of having negative effects on the patient, such as decreased psychological and physical health and increased mortality [5,6]. Informal caregivers may experience a rapid reduction in their everyday physical and emotional burdens as a result of institutionalization [7-9], but there may also be an increase or possible chronification of stress symptoms or depression [7-14]. Often, the tasks of and the strains on the family members are not solved by the admission of the patient into a nursing home, but are rather shifted to another area, such as visits to the home, care activities that continue, or discussions with the home staff [15-18].

Institutionalization of dementia patients is problematic from 2 perspectives:

(1) In industrial countries like Germany, the majority of care receivers and their caregivers prefer care at home $[19,20]$. The caregivers' final decision to institutionalize dementia patients is often difficult and laden with conflict [21,22].

(2) The institutionalized care of dementia patients represents the largest portion of direct costs in the care of the elderly, both for social care insurance and for the family members themselves [23, 24].

In order to have an effect on the process of institutionalization, such as by postponing it or by helping to make this difficult transition go more smoothly, it is necessary to identify the predictors that can be influenced by interventions. The psychosocial and medical circumstances under which institutionalization takes place have been examined in numerous studies. For one thing, dementia itself is often a strong predictor of institutionalization of elderly people [25-30]. In addition to functional impairment in the activities of daily living (ADL) or instrumental activities of daily living (IADL) [30,31] and the extent of cognitive impairment [1, 26, 27, 32-34], dementia patients' behavioral problems [19, 33, 35-37], such as aggression [38] or depression [32, 39-41], are important predictors. Like limited physical health or comorbidities [27, 40-42], such as urinary or fecal incontinence [40,43], unexpected events, such as hospitalization [44], can influence the final institutionalization. Sociodemographic predictors, such as living alone [34], the absence of a spouse [1, 45, 46], older age [26-28, 31, 40,41], the socioeconomic status [47], the place of residence [34], employment [19], ethnicity [27, 28], or gender [31, 40, 45, 48], can play a role in the process of institutionalization, too. Likewise, characteristics of the care situation are often important predictors, for example, the presence of helpers [19] or the use of community-based care [45]. Caregiver burden has been found to be an important independent predictor [32], on the one hand, and a mediator, on the other [37, 39].

These results indicate that institutionalization is determined multifactorially by a number of single influencing factors. In the literature, predictors of institutionalization have been examined in different ways, both methodologically and qualitatively, often not in theorybased ways, and seldom with multivariate analyses that include a large number of variables. 
Eska et al.: Predictors of Institutionalization of Dementia Patients in Mild and Moderate Stages: A 4-Year Prospective Analysis

For this reason, the present study followed a methodologically elaborated, theory-based, multivariate research approach.

Based on a literature review, Luppa et al. [49] presented a differentiated model for predicting institutionalization of dementia patients. In accordance with the models proposed by Andersen [50], Pearlin et al. [51], and Pruchno et al. [52], Luppa et al. [49] subdivided the predictors of institutionalization into 'predisposing variables', 'need variables', and 'enabling variables' (fig. 1). The predisposing variables include sociodemographic characteristics of the patients and caregivers, sociocultural aspects, the socioeconomic status, and characteristics of the relationship between the patients and caregivers. The need variables describe the subjective evaluation of the illness by the patients and caregivers and the objectively estimated need for help. Luppa et al. [49] further subdivided the need variables into 'primary stressors' (dementia-related aspects and caregiving-related aspects) and 'secondary stressors' (the caregivers' evaluation of the burden caused by the care situation). The enabling variables denote personal and social resources as well as community-based care offers. Finally, Luppa et al. [49] noted a 'desire for institutionalization', which precedes the final institutionalization. Their predictor model offers a structured overview and categorization of predictors and thus provides a starting point for a comprehensive conceptual elucidation of institutionalization.

The current paper refers to a large sample and a broad set of variables from 3 data sources (a baseline caregiver interview, a baseline assessment from the general practitioner, and health insurance data), and it contains the use of different assessment methods. This made it possible to pursue the following aims:

(1) to determine independent predictors of institutionalization by using multivariate regression analysis and

(2) to examine the validity of the predictor model by Luppa et al. [49].

\section{Methods}

\section{Design and Participants}

The data for the study presented here were obtained from a 3-armed, cluster-randomized, controlled trial called the 'IDA project' (Dementia Care Initiative in Primary Practice), which had been developed to evaluate a counseling program for family caregivers of dementia patients [53] (trial registration: ISRCTN68329593). There was 1 control group (group A: standard treatment by the general practitioners) and 2 intervention groups (group B: standard treatment, a caregiver support group, and family counseling after 1 year, and group C: standard treatment, a caregiver support group, and family counseling from baseline). More information about the counseling program can be found in Grossfeld-Schmitz et al. [54]. In the IDA project, no statistically significant differences were found between the groups [55]. Additional aims of the IDA project were to investigate whether the program had an effect on institutionalization and to examine the costs of care for dementia patients in a community setting $[23,55]$. For this purpose, 129 cooperating and trained general practitioners in the region of Middle Franconia, Bavaria, Germany, recruited 390 dementia patients and their

Fig. 1. Capital letters represent variables in the model by Luppa et al. [49]. Variables in our study are in parentheses (...), 39 variables are shown (the adjustment variables study arm B and C are excluded). Significant predictors from our multivariate analysis are given in bold. Some variables cannot be assigned to the predictor model by Luppa et al. [49]: EQ-5D (P), Incalzi Comorbidity Index, antidementia drugs, psychopharmaceutical drugs, and nonpharmacological therapy. Black boxes contain suggestions for modifications of the model by Luppa et al. [49]. Arrows indicate shifts within the modifications. P = Patient; CG = caregiver. 
Dementia

and Geriatric

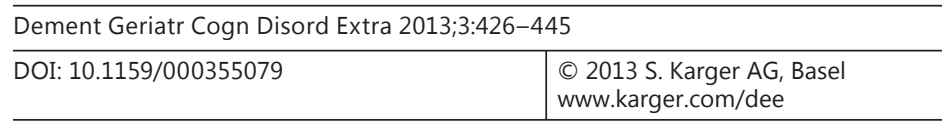

Eska et al.: Predictors of Institutionalization of Dementia Patients in Mild and Moderate Stages: A 4-Year Prospective Analysis
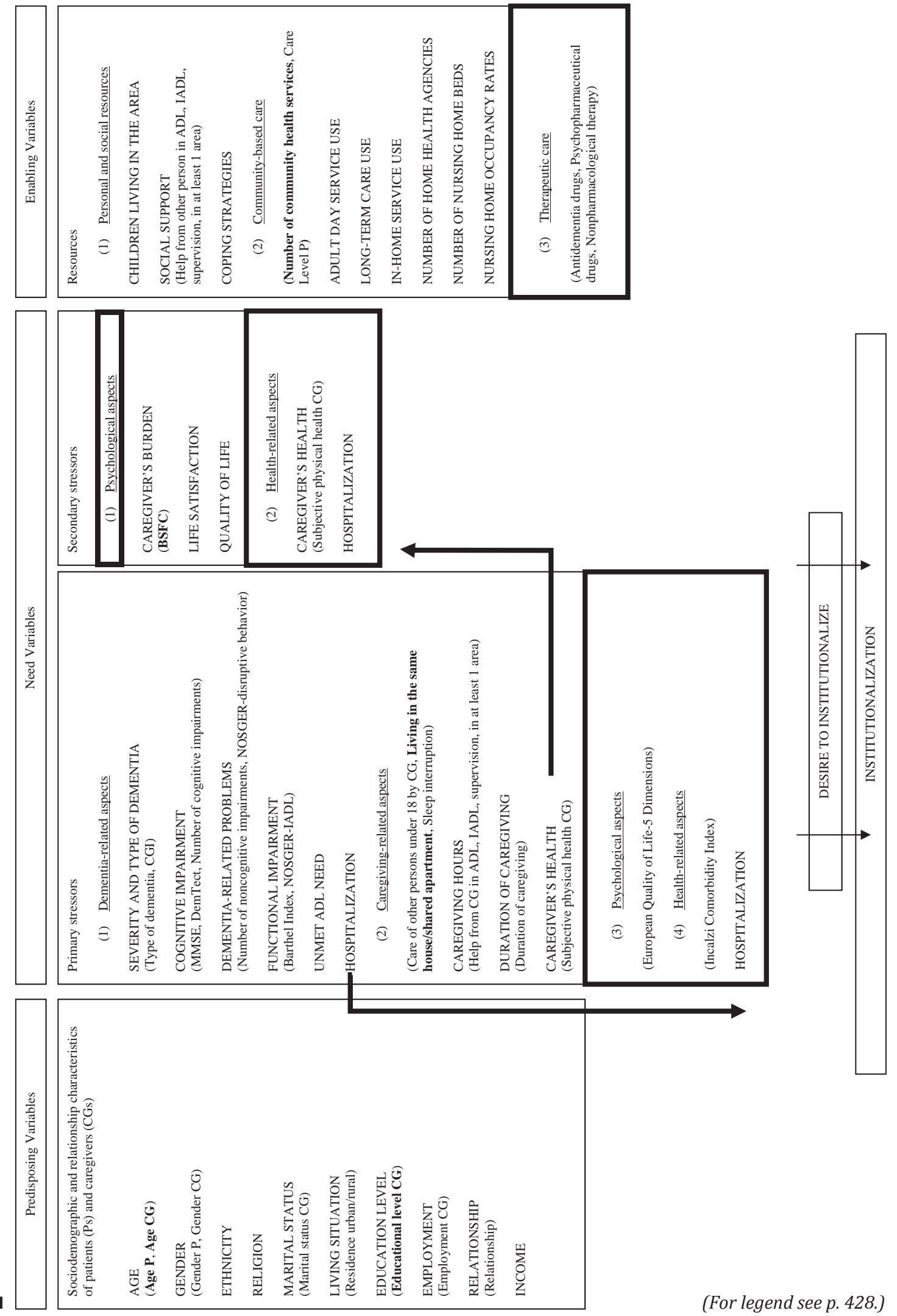

KARGER 
Eska et al.: Predictors of Institutionalization of Dementia Patients in Mild and Moderate Stages: A 4-Year Prospective Analysis

informal caregivers [56]. The intervention program was conducted over a period of 2 years. Patients were only included in the IDA project if they had physician-diagnosed mild or moderate primary dementia, were at least 65 years old, had an AOK Bavaria Statutory Health Insurance, were still living at home, and had an informal caregiver. Additionally, written informed consent of patients and their caregivers was also required before inclusion in the study. Patients were excluded if they had a terminal illness, if institutionalization had already been planned, or if they were not able or willing to provide informed consent. The IDA project was approved by the Ethics Committee at the Bavarian Chamber of Physicians (No. 05029) and was conducted in accordance with the Declaration of Helsinki.

The present study investigated the extent to which variables recorded at baseline could predict institutionalization after a period of 4 years. The baseline data were comprised of a caregiver interview, a general practitioner's assessment, and health insurance data. The sample consisted of those 357 cases from the IDA project for whom all baseline data were available, including the informed consent statements of the patients and caregivers.

\section{Instruments}

Mini-Mental State Examination

The Mini-Mental State Examination (MMSE) [57] was used for dementia screening. The score ranges from 0 (= maximal cognitive impairment) to 30 points (= maximal cognitive performance). Patients with mild (18-24 points) or moderate (10-17 points) dementia were included in our study.

DemTect

DemTect [58] is another screening instrument for dementia and consists of 5 subtests. They cover the areas 'verbal memory', 'cognitive flexibility', 'word fluency', 'working memory', and 'long-term memory'. The DemTect is more sensitive to mild dementia than the MMSE. The evaluation can be made separately for people $<60$ versus $>60$ years of age; the maximum score is 18 points. The sum score allows to draw conclusions concerning suspected dementia ( $\leq 8$ points), mild cognitive impairment ( $9-12$ points), or age-appropriate cognitive performance (13-18 points).

Incalzi Comorbidity Index

The Incalzi Comorbidity Index $[59,60]$ is used to weight comorbidities. The procedure assigns a relative mortality risk of 1-6 to a total of 52 diseases. Category 1, which indicates the lowest mortality risk, includes for example hypertension and ulcerative colitis. Category 6 , with the highest relative mortality risk, includes for example acute leukemia and stage III multiple myeloma. The sum score for the mortality risk was calculated from the diseases documented in the health insurance data according to the ICD-10.

\section{Clinical Global Impression}

The Clinical Global Impression (CGI) [61] records the physician's overall clinical impression. Only the item 'severity of the disease' was used in the present study. The 7-step classification consists of 'healthy' $(=1)$, 'borderline' (=2), 'slightly ill' (=3), 'moderately ill' (= 4 ), 'obviously ill' (=5), 'seriously ill' (=6), 'extremely seriously ill' (=7), and, additionally, 'cannot be rated' $(=0)$.

European Quality of Life - 5 Dimensions

The European Quality of Life - 5 Dimensions (EQ-5D) is used to measure the healthrelated quality of life of patients $[62,63]$. The assessment of health according to the EuroQol classification is made for the dimensions 'mobility', 'self-care', 'everyday activities', 'pain/ 
discomfort', and 'anxiety/depression' using a 3-step scale (no difficulties vs. moderate or some difficulties vs. extreme difficulties). To calculate the utilities, the German tariff was used, which is based on time trade-off, yielding utility values ranging from -0.02 to 1 [64]. As the self-rating of dementia patients may be invalid or erroneous $[65,66]$, the evaluation of quality of life was conducted by the caregivers.

Barthel Index

The Barthel Index [67] is a widely used observer rating scale for measuring the independence of patients in fundamental ADL. Basic, everyday, practical abilities are rated on a 2-step ( 0 or 5 points) to 4 -step rating scale $(0,5,10$, or 15 points) for 10 functional areas: 'eating', 'sitting up and changing chairs', 'washing', 'using the toilet', 'bathing and showering', 'getting up and walking', 'climbing stairs', 'dressing and undressing', 'fecal continence', and 'urinary continence'. The sum score ranges from 0 (= dependent in all areas) to 100 points (= completely independent in all ADL functions). The Barthel items were presented in a form that was adequate for the caregivers to rate the functional independence of the patients in the interview.

Nurses' Observation Scale for Geriatric Patients

With the Nurses' Observation Scale for Geriatric Patients (NOSGER) [68], caregivers describe behavioral problems and changes in behavior of geriatric patients with regard to daily functioning on several dimensions: 'memory,' 'IADL', 'ADL', 'mood', 'social behavior', and 'disruptive behavior'. In our study, we used the 2 subscales 'disruptive behavior' and 'IADL', consisting of 5 questions each. The informal caregivers rated the relevant behaviors on a 5 -step scale ranging from 1 (= always) to $5(=$ never $)$ in reference to the last 2 weeks. The score for each subscale ranged from 5 (= no disturbance/fully independent) to 25 (= maximum disturbance/fully dependent) [69].

Care Time

The Resource Utilization in Dementia (RUD) [70-73] scale, modified by Neubauer et al. $[74,75]$, is used to determine the time spent on care activities. It is based on a reliable and valid questionnaire recording the time spent on informal care activities by the main family caregiver and other informal caregivers. The informal care activities include the 3 categories ADL, IADL, and supervision. In this study, we used a rough dichotomous division, indicating whether the main family caregiver or another informal caregiver gave any help in these areas.

Burden Scale for Family Caregivers

The Burden Scale for Family Caregivers (BSFC) [76] includes 28 items for the measurement of caregiver burden by self-report. The items cover the entire spectrum of burden causes, especially in the areas 'expenditure of emotional and physical energy', 'relationship between caregiver and patient', 'changes in the socioeconomic situation', 'overload', and 'role identification'. The items are rated on a scale from 0 (= definitely disagree) to 3 (= definitely agree). The sum score ranges from 0 to 84 points with higher values indicating greater caregiver burden. The scale is validated using the increasing risk for psychosomatic symptoms in the case of increasing subjective burden.

\section{Other Measures}

Care Level

The level of care in Germany is categorized by the degree of care required due to physical or psychological impairments. Trained experts of the Medical Service of the Health Insurance make the decisions about the Care Level: Care Level 0 indicates no/low impairment, Care Level 1 indicates mild impairment, Care Level 2 indicates moderate impairment, and Care Level 3 
Eska et al.: Predictors of Institutionalization of Dementia Patients in Mild and Moderate Stages: A 4-Year Prospective Analysis

indicates severe impairment. The decision is based on the need for help in ADL and household duties. The daily amount of time spent on the care of patients in Care Level 1 must average at least $1.5 \mathrm{~h}$, it is at least $3.0 \mathrm{~h}$ in Care Level 2, and it is at least $5.0 \mathrm{~h}$ in Care Level 3. The Care Level determines the amount of financial services paid by the care insurance [77]. The Care Level is strongly associated with impairments in ADL functioning $(\eta=0.75$ with the Barthel Index in our study), and it is only mildly associated with cognitive decline ( $\eta=0.37$ with the MMSE).

\section{Number of Community Health Services}

The variable 'number of community health services' represents the total number of community-based health services used by patients and caregivers (range: $0-10$ ). These are: family counseling, support group, home nursing, home help, Meals on Wheels, voluntary help service, care group, adult daycare, day hospital, and short-term residential care.

Number of Cognitive Impairments

The general practitioners assessed the number of cognitive impairments (range: 0-5); they are: disorientation, agnosia, impaired executive functions, apraxia, and aphasia.

Number of Noncognitive Impairments

The number of noncognitive impairments (range: $0-7$ ) is calculated based on the following symptoms: anxiety, depression, aggression, agitation/restlessness, tendency to run away, insomnia, and delusions.

\section{Events}

The events 'institutionalization', 'death', 'dropout', and 'study completion without event' were registered in the 4-year follow-up with the date of the event.

Conceptual Framework

A total of 41 variables were analyzed in this study (fig. 1). These 41 variables consisted of 9 predisposing variables according to the model by Luppa et al. [49], 19 need variables [primary stressors - dementia-related aspects (9), caregiving-related aspects (9), and 1 secondary stressor], 6 enabling variables [resources - personal and social (4) and communitybased care (2)], and 7 variables that were not classifiable according to the model by Luppa et al. [49]: EQ-5D (patient), Incalzi Comorbidity Index, psychopharmaceutical drugs, antidementia drugs, nonpharmacological therapy, study arm B, and study arm C.

\section{Data Recording}

The assessments by the general practitioners at baseline included sociodemographic information about the patients (urban/rural residence, age, and gender), the inclusion criteria, ICD-10 criteria for dementia, and attendant symptoms (disorientation, agnosia, impaired executive functions, apraxia, aphasia, anxiety, depression, aggression, agitation/ restlessness, tendency to run away, insomnia, and delusions). Moreover, the general practitioners performed the screening procedures of the MMSE, DemTect, and CGI as well as the additional medical examinations to clarify the type of dementia. They also assessed comorbidities and the use of drug and non-drug therapy.

In a computer-based telephone interview with the informal caregivers, trained interviewers recorded data on the caregivers' sociodemography, the care situation, the patients' EQ-5D, Barthel Index, and NOSGER, the BSFC and the caregivers' physical health, the care time invested by the informal caregivers as well as the use of community health services. From the health insurance data, we were able to obtain information about whether institutionalization had taken place or the patients had died within the 4-year period. 
Eska et al.: Predictors of Institutionalization of Dementia Patients in Mild and Moderate Stages: A 4-Year Prospective Analysis

\section{Statistical Analysis}

General Description

For predictive analyses, the statistical procedure of Cox regression was used [78] with 'institutionalization' as the dependent variable. The events 'death', 'other dropout', or 'end of study' were censored, and the observation period was counted in days from baseline to the occurrence of the target or censoring event. The study arms of the IDA project (groups B and $C$ as dummy variables) and patient's and caregiver's age and gender were used as adjustment variables in all regression analyses. Missing values were imputed based on an expectationmaximization algorithm [79] using available information from the general practitioners' baseline assessments, telephone interviews with the caregivers, and health insurance data. Only single missing items had to be imputed instead of whole interviews.

\section{Generation of Sum Scores}

Several single variables were combined into sum scores: 'number of community health services', 'number of cognitive impairments', and 'number of noncognitive impairments'. To justify the summation of these single variables, the direction of the predictive influence of each single variable (i.e. the augmentation or reduction of risk) was checked by Cox regression. If the predictive direction of the single variables was the same or not significantly different, the sum score was computed.

Univariate Analysis

To achieve valid results, the number of variables in the Cox regression had to be limited. Usually, the number of covariates should not make up $>10 \%$ of the target events [80]. In our case, this meant a limit of 8 covariates for the multivariate model. For this reason, a 'univariate' Cox regression (method enter) was first conducted to individually check all 41 independent variables for their influence on the risk of institutionalization. Only those variables with a significant influence (cutoff $\mathrm{p} \leq 0.05$ ) were used in further analyses (in addition to the adjustment variables).

\section{Multicollinearity}

To avoid redundancy, the significant variables of the univariate analysis were checked for multicollinearity. Variables with a correlation coefficient of $r<0.50$ were rated as not multicollinear and were retained in the model. At a moderate correlation of $r \geq 0.50$, multicollinearity was assumed, and those variables with the greatest predictive influence on institutionalization were retained in further analyses, whereas those with lower significance were excluded.

\section{Multivariate Analysis}

The remaining variables were then analyzed together in a multivariate Cox regression model. In this predictor model, the adjustment variables were included in the Cox regression in an initial block using the method enter, the other covariates were integrated together into the model in a second block using the method stepwise backward $L R$ [81]. The inclusion cutoff was set at $\mathrm{p} \leq 0.01$ and the exclusion cutoff at $\mathrm{p} \leq 0.05$.

\section{Sensitivity Analysis}

Two sensitivity analyses were performed. First, we checked the predictive influence of single items from the Barthel Index within the univariate analysis (e.g. urinary and fecal incontinence). Second, in the sensitivity analysis within the multivariate analysis, we changed the inclusion cutoff to $\mathrm{p} \leq 0.05$ and the exclusion cutoff to $\mathrm{p} \leq 0.10$ in the multivariate Cox regression to test the stability of the multivariate predictor model. IBM SPSS Statistics 19 was used to compute the statistical analyses. 
Table 1. Patient and caregiver characteristics

\section{Sociodemographic and relationship characteristics of $P$ and CG}

Age P, years

$80.2 \pm 6.7$

Female P

$241(67.5)$

Age CG, years

$59.2 \pm 13.4$

Female CG

$262(73.4)$

Relationship (spouse) ${ }^{\mathrm{a}}$

$115(32.2)$

Marital status CG (married) ${ }^{\mathrm{b}}$

$289(81.0)$

Educational level CG (higher than elementary)

$117(32.8)$

Employment CG (employed)

$128(35.9)$

Residence CG (urban) ${ }^{\mathrm{d}}$

$68(19.0)$

\section{Primary stressors - dementia-related aspects}

Type of dementia (degenerative) ${ }^{\mathrm{e}}$

Dementia screening with MMSE

Dementia screening with DemTect

$18.7 \pm 3.8$

Cognitive impairments ${ }^{\mathrm{f}}$

$5.7 \pm 3.5$

Noncognitive impairments ${ }^{\mathrm{g}}$

$2.1 \pm 1.3$

CGI

$1.6 \pm 1.6$

$4.2 \pm 1.1$

NOSGER - disruptive behavior

$9.5 \pm 3.5$

NOSGER - IADL

$15.8 \pm 5.4$

Barthel Index

$73.0 \pm 26.5$

\section{Primary stressors - caregiving-related aspects}

CG and P living in the same house/shared apartment (yes)

$244(68.3)$

Duration of caregiving by the CG until baseline, months

$37.8 \pm 48.0$

Care of other persons under 18 years by CG (yes)

$86(24.1)$

Help from CG in ADL (yes)

Help from CG in IADL (yes)

$245(68.6)$

$331(92.7)$

Help from CG in supervision (yes)

$135(37.8)$

$331(92.7)$

Help from CG in at least 1 area (ADL, IADL, or supervision) (yes)

$122(34.2)$

Sleep interruption for CG due to care activities (yes)

$217(60.8)$

\section{Secondary stressors}

BSFC

$24.9 \pm 17.3$

\section{Resources - personal and social}

Help from other informal CG in ADL (yes)

Help from other informal CG in IADL (yes)

$115(32.2)$

$180(50.4)$

Help from other informal CG in supervision (yes)

$68(19.0)$

Help from other person in at least 1 area (ADL, IADL, or supervision) (yes)

$212(59.4)$

\section{Resources - community-based care}

Community health services

$0.6 \pm 0.9$

Care Level P (Level 1, 2, or 3)

$153(42.9)$

Not classifiable by the model by Luppa et al. [49]

EQ-5D, health-related quality of life P

$0.55 \pm 0.31$

Incalzi Comorbidity Index $P$

$3.6 \pm 2.1$

Antidementia drugs ${ }^{j} \mathrm{P}$ (yes)

Psychopharmaceutical drugs ${ }^{\mathrm{k}} \mathrm{P}$ (yes)

$170(47.6)$

$107(30.0)$

Nonpharmacological therapy ${ }^{1} \mathrm{P}$ (yes)

$46(12.9)$

Study arm B

$103(28.9)$

Study arm C

$102(28.6)$ 
Eska et al:: Predictors of Institutionalization of Dementia Patients in Mild and Moderate Stages: A 4-Year Prospective Analysis

\section{Results}

\section{Sample Characteristics}

The patients' mean age was 80.2 years; two-thirds (67.5\%) were women (table 1). According to the MMSE, mild dementia was present in $64.1 \%(n=327)$ of the cases and moderate dementia in $35.9 \%(n=30)$. In $42.9 \%$ of the dementia patients, the impairment in ADL was so great that they attained a Care Level under the German health system and thus received support from the health care insurance. Care Level 1 (= mild impairment) was assigned to $16.0 \%(\mathrm{n}=57)$, Care Level 2 (= moderate impairment) to $18.5 \%(\mathrm{n}=66)$, and Care Level 3 (= severe impairment) to $8.4 \%(n=30)$ of the patients. Although dementia was diagnosed in all patients, only about half of the patients were being treated with antidementia drugs $(47.6 \%)$. After 4 years, $23.5 \%(n=84)$ of the patients were institutionalized, $34.7 \%$ $(\mathrm{n}=124)$ had died at home, and 9.2\% $(\mathrm{n}=33)$ had died after institutionalization. For $40.3 \%$ $(\mathrm{n}=144)$ of the patients, the study ended without any event, and $1.4 \%(\mathrm{n}=5)$ of the patients dropped out because of the revocation of the informed consent.

The caregivers' mean age was 59.2 years; $73.4 \%$ were women. The majority was married (81\%), not employed (64.1\%), and had a low $(67.2 \%, \mathrm{n}=240)$ or moderate $(24.4 \%, \mathrm{n}=87)$ educational level. In $68.3 \%$ of the cases, the caregiver lived in the same house as the patient or in a shared apartment. At baseline, $92.7 \%$ of the caregivers assisted the dementia patients in the area ADL, IADL, or supervision; in 59.4\% of the cases, another informal caregiver helped in 1 of these areas. $34.2 \%$ of the caregivers reported interruptions in their sleep at night because of care-related activities.

\section{Univariate Analysis}

The results of the univariate analysis of the total number of independent study variables $(n=41)$ are given in table 2 . The following 13 covariates emerged as significant $(\mathrm{p} \leq 0.05)$ and were therefore retained in further analyses as potential predictor variables: patient's age,

\section{(Footnote to table 1.)}

$\mathrm{P}=$ Patient $\mathrm{CG}=$ caregiver .

The results are given as numbers with percentages in parentheses or as means \pm SD (= standard deviation).

a Non-spouse: mother, mother-in-law, father, father-in-law, other.

${ }^{\mathrm{b}}$ Not married: single, widowed, divorced.

${ }^{\mathrm{c}}$ Higher than elementary: standard certificate, high school, university.

d Urban: 100,000 residents or more.

e Degenerative: Alzheimer's dementia, other degenerative dementia, mixed forms.

${ }^{\mathrm{f}}$ Cognitive impairments: disorientation $(201 ; 56.3 \%)$, agnosia $(76 ; 21.3 \%)$, impaired executive functions $(294 ; 82.4 \%)$, apraxia $(105 ; 29.4 \%)$, aphasia $(89 ; 24.9 \%)$.

g Noncognitive impairments: anxiety $(123 ; 34.5 \%)$, depression $(117 ; 32.8 \%)$, aggression $(55 ; 15.4 \%)$, agitation/restlessness $(97 ; 27.2 \%)$, tendency to run away $(30 ; 8.4 \%)$, insomnia $(147 ; 41.2 \%)$, delusions $(17$; $4.8 \%)$.

${ }^{\mathrm{h}}$ Suboptimal/poor $=0$.

${ }^{\mathrm{i}}$ Community health services: family counseling $(10 ; 2.8 \%)$, support group $(7 ; 2.0 \%)$, home nursing (79; $22.1 \%)$, home help $(27 ; 7.6 \%)$, Meals on Wheels $(24 ; 6.7 \%)$, voluntary help service $(5 ; 1.4 \%)$, care group (4; $1.1 \%)$, adult daycare $(10 ; 2.8 \%)$, day hospital $(5 ; 1.4 \%)$, short-term residential care $(25 ; 7.0 \%)$.

j Donepezile, galantamine, rivastigmine, and memantine, others: piracetam, gingko, and biloba.

${ }^{\mathrm{k}}$ All other drugs with psychotropic effects.

${ }^{1}$ Cited were: occupational therapy, movement therapy, cognitive stimulation, social activation, diet, and massages. 
Table 2. Results of the univariate predictor analysis

\begin{tabular}{|c|c|c|c|c|c|c|c|}
\hline \multirow[t]{2}{*}{ Variable } & \multirow[t]{2}{*}{ B } & \multirow[t]{2}{*}{ SE } & \multirow[t]{2}{*}{ Wald } & \multirow[t]{2}{*}{ Sign } & \multirow[t]{2}{*}{$\operatorname{Exp}(B)$} & \multicolumn{2}{|c|}{$\begin{array}{l}95.0 \% \mathrm{CI} \\
\text { for } \operatorname{Exp}(\mathrm{B})\end{array}$} \\
\hline & & & & & & lower & upper \\
\hline \multicolumn{8}{|c|}{ Sociodemographic and relationship characteristics of $P$ and CG } \\
\hline Age $P$ & 0.07 & 0.02 & 15.28 & $<0.001$ & 1.07 & 1.04 & 1.11 \\
\hline Gender P & 0.34 & 0.31 & 1.16 & 0.28 & 1.40 & 0.76 & 2.58 \\
\hline Age $C G$ & 0.02 & 0.01 & 4.24 & 0.040 & 1.02 & 1.00 & 1.04 \\
\hline Gender CG & 0.18 & 0.28 & 0.41 & 0.52 & 1.20 & 0.69 & 2.07 \\
\hline Relationship ${ }^{\mathrm{a}}$ & -1.15 & 0.50 & 5.32 & 0.021 & 0.32 & 0.12 & 0.84 \\
\hline Marital status CG & -0.13 & 0.27 & 0.24 & 0.62 & 0.88 & 0.52 & 1.48 \\
\hline Educational level CG & 0.79 & 0.24 & 10.94 & 0.001 & 2.19 & 1.38 & 3.49 \\
\hline Employment CG & 0.49 & 0.30 & 2.74 & 0.10 & 1.63 & 0.91 & 2.92 \\
\hline Residence (urban/rural) CG & 0.52 & 0.26 & 3.91 & 0.048 & 1.67 & 1.01 & 2.79 \\
\hline \multicolumn{8}{|l|}{ Primary stressors - dementia-related aspects } \\
\hline Type of dementia & 0.35 & 0.27 & 1.63 & 0.20 & 1.41 & 0.83 & 2.41 \\
\hline MMSE & -0.05 & 0.03 & 2.73 & 0.10 & 0.96 & 0.91 & 1.01 \\
\hline DemTect & -0.08 & 0.03 & 5.99 & 0.014 & 0.92 & 0.86 & 0.98 \\
\hline Cognitive impairments & 0.01 & 0.08 & 0.01 & 0.91 & 1.01 & 0.86 & 1.19 \\
\hline Noncognitive impairments & 0.05 & 0.07 & 0.50 & 0.48 & 1.05 & 0.92 & 1.21 \\
\hline CGI & 0.13 & 0.10 & 1.62 & 0.20 & 1.14 & 0.93 & 1.39 \\
\hline NOSGER - disruptive behavior & 0.03 & 0.03 & 0.72 & 0.40 & 1.03 & 0.97 & 1.09 \\
\hline NOSGER - IADL & 0.04 & 0.02 & 3.96 & 0.047 & 1.04 & 1.00 & 1.09 \\
\hline Barthel Index & 0.00 & 0.00 & 0.07 & 0.80 & 1.00 & 0.99 & 1.01 \\
\hline \multicolumn{8}{|l|}{ Primary stressors - caregiving-related aspects } \\
\hline Living in the same house/shared apartment & -0.80 & 0.26 & 9.75 & 0.002 & 0.45 & 0.27 & 0.74 \\
\hline Duration of caregiving & 0.00 & 0.00 & 0.00 & 0.96 & 1.00 & 0.99 & 1.00 \\
\hline Care of other persons under 18 by CG & -0.17 & 0.32 & 0.29 & 0.59 & 0.84 & 0.45 & 1.58 \\
\hline Help from $C G$ in $A D L^{\mathrm{b}}$ & 0.53 & 0.27 & 3.91 & 0.048 & 1.70 & 1.01 & 2.87 \\
\hline Help from CG in IADL & 0.97 & 0.59 & 2.67 & 0.10 & 2.63 & 0.82 & 8.39 \\
\hline Help from CG in supervision & 0.22 & 0.23 & 0.93 & 0.34 & 1.25 & 0.80 & 1.95 \\
\hline Help from CG in at least 1 area & 0.97 & 0.59 & 2.67 & 0.10 & 2.63 & 0.82 & 8.39 \\
\hline Sleep interruption & 0.13 & 0.24 & 0.28 & 0.60 & 1.13 & 0.71 & 1.81 \\
\hline Subjective physical health CG & 0.31 & 0.23 & 1.72 & 0.19 & 1.36 & 0.86 & 2.14 \\
\hline \multicolumn{8}{|l|}{ Secondary stressors } \\
\hline$B S F C$ & 0.02 & 0.01 & 7.70 & 0.006 & 1.02 & 1.01 & 1.03 \\
\hline \multicolumn{8}{|l|}{ Resources - personal and social } \\
\hline Help from other informal CG in ADL & 0.13 & 0.23 & 0.32 & 0.57 & 1.14 & 0.72 & 1.81 \\
\hline Help from other informal CG in $I A D L^{\mathrm{c}}$ & 0.52 & 0.23 & 5.16 & 0.023 & 1.68 & 1.07 & 2.63 \\
\hline Help from other informal CG in supervision & 0.23 & 0.28 & 0.67 & 0.41 & 1.25 & 0.73 & 2.16 \\
\hline Help from other informal CG in at least 1 area & 0.59 & 0.24 & 6.02 & 0.014 & 1.80 & 1.13 & 2.89 \\
\hline \multicolumn{8}{|l|}{ Resources - community-based care } \\
\hline Community health services & 0.61 & 0.09 & 42.74 & $<0.001$ & 1.85 & 1.54 & 2.22 \\
\hline Care Level P & 0.21 & 0.23 & 0.85 & 0.36 & 1.23 & 0.79 & 1.93 \\
\hline \multicolumn{8}{|c|}{ Not classifiable by the model by Luppa et al. [49] } \\
\hline EQ-5D P & -0.43 & 0.36 & 1.49 & 0.22 & 0.65 & 0.32 & 1.30 \\
\hline Incalzi Comorbidity Index & -0.00 & 0.06 & 0.00 & 0.98 & 1.00 & 0.90 & 1.11 \\
\hline Antidementia drugs & 0.37 & 0.22 & 2.69 & 0.10 & 1.44 & 0.93 & 2.24 \\
\hline Psychopharmaceutical drugs & 0.32 & 0.24 & 1.84 & 0.18 & 1.38 & 0.87 & 2.20 \\
\hline Nonpharmacological therapy & 0.14 & 0.33 & 0.18 & 0.67 & 1.15 & 0.60 & 2.21 \\
\hline Study arm B & 0.14 & 0.27 & 0.26 & 0.61 & 1.15 & 0.67 & 1.96 \\
\hline Study arm C & 0.18 & 0.26 & 0.44 & 0.51 & 1.19 & 0.71 & 2.00 \\
\hline
\end{tabular}


caregiver's age, relationship, caregiver's educational level, urban/rural residence (all predisposing variables), DemTect, NOSGER - IADL, living in the same house/shared apartment, help from the caregiver in ADL, BSFC (all need variables), help from other informal caregivers in IADL, help from other informal caregivers in at least 1 area, and the number of community health services (all enabling variables).

To test the predictive influence of urinary and fecal incontinence on institutionalization, a univariate sensitivity analysis of the single Barthel items was conducted, but only the 'bathing/showering' item (dichotomized) reached statistical significance (B $=0.53, \mathrm{SE}=0.27$, Wald $=4.01$, d.f. $=1, \mathrm{p}=0.045, \operatorname{Exp}(\mathrm{B})=1.71,95.0 \% \mathrm{CI}=1.01-2.87)$.

\section{Multicollinearity}

Due to multicollinearity (with correlations between $r=-0.58$ and 0.83 , see the legend of table 2), 3 variables dropped out from further analyses: relationship (predisposing variable), help from the caregiver in ADL (need variable), and help from other informal caregivers in IADL (enabling variable).

\section{Multivariate Analysis}

The Cox regression of the remaining variables ( 6 adjustment variables in addition to 8 univariate significant variables) revealed 6 significant predictors of institutionalization after 4 years (table 3): (1) educational level: with a higher educational level of the caregiver, the risk of institutionalization increased; (2) living in the same house/shared apartment: if the caregiver and patient lived apart, the risk increased; (3) BSFC: a high subjective caregiver burden increased the risk; (4) the number of community health services: the more formal community-based health care services were used by the patient and caregiver, the greater the risk, and the 2 adjustment variables (5) patient's age and (6) caregiver's age were also found to be significant in this analysis - as they increased, so did the risk of institutionalization. The significant predictors in the multivariate analysis are presented in bold print in figure 1 .

Finally, a sensitivity analysis with more generous cutoffs (inclusion cutoff $\mathrm{p} \leq 0.05$, exclusion cutoff $\mathrm{p} \leq 0.10$ ) was performed to test the stability of the model. The Cox regression was found to be stable as the 6 known covariates once again reached statistical significance in predicting institutionalization. One additional variable remained in this model: DemTect $(\mathrm{B}=-0.07, \mathrm{SE}=0.03$, Wald $=3.72$, d.f. $=1, \mathrm{p}=0.054, \operatorname{Exp}(\mathrm{B})=0.94,95.0 \% \mathrm{CI}=0.88-1.00)$.

\section{Conceptual Framework}

The results confirm the multifactorial significant influence from statistically independent variables on institutionalization, representing all areas of the model by Luppa et al. [49] (see fig. 1): predisposing variables (patient's age, caregiver's age, educational level); need variables - primary stressor (living in the same house/shared apartment) and secondary stressor (BSFC), and enabling variable (the number of community health services).

(Footnote to table 2.)

$\mathrm{P}=$ Patient; $\mathrm{CG}=$ caregiver .

$\mathrm{B}=$ Regression coefficient; $\mathrm{SE}=$ standard error; Wald = Wald significance test; Sign = significance level (p); $\operatorname{Exp}(B)=$ hazard ratio; $\mathrm{CI}=$ confidence interval.

$\mathrm{n}=357$, d.f. $=1$.

Variables in italics are statistically significant; $\mathrm{p} \leq 0.05$.

Multicollinearity analysis: dropped out due to multicollinearity: ${ }^{a}$ correlation with Age CG $-\mathrm{r}=0.74$ and correlation with Gender P $-r=-0.58$; ${ }^{b}$ correlation with NOSGER - IADL $-r=0.66$; $^{\mathrm{c}}$ correlation with Help from other informal CG in at least 1 area $-r=0.83$. 
Table 3. Results of the multivariate predictor analysis

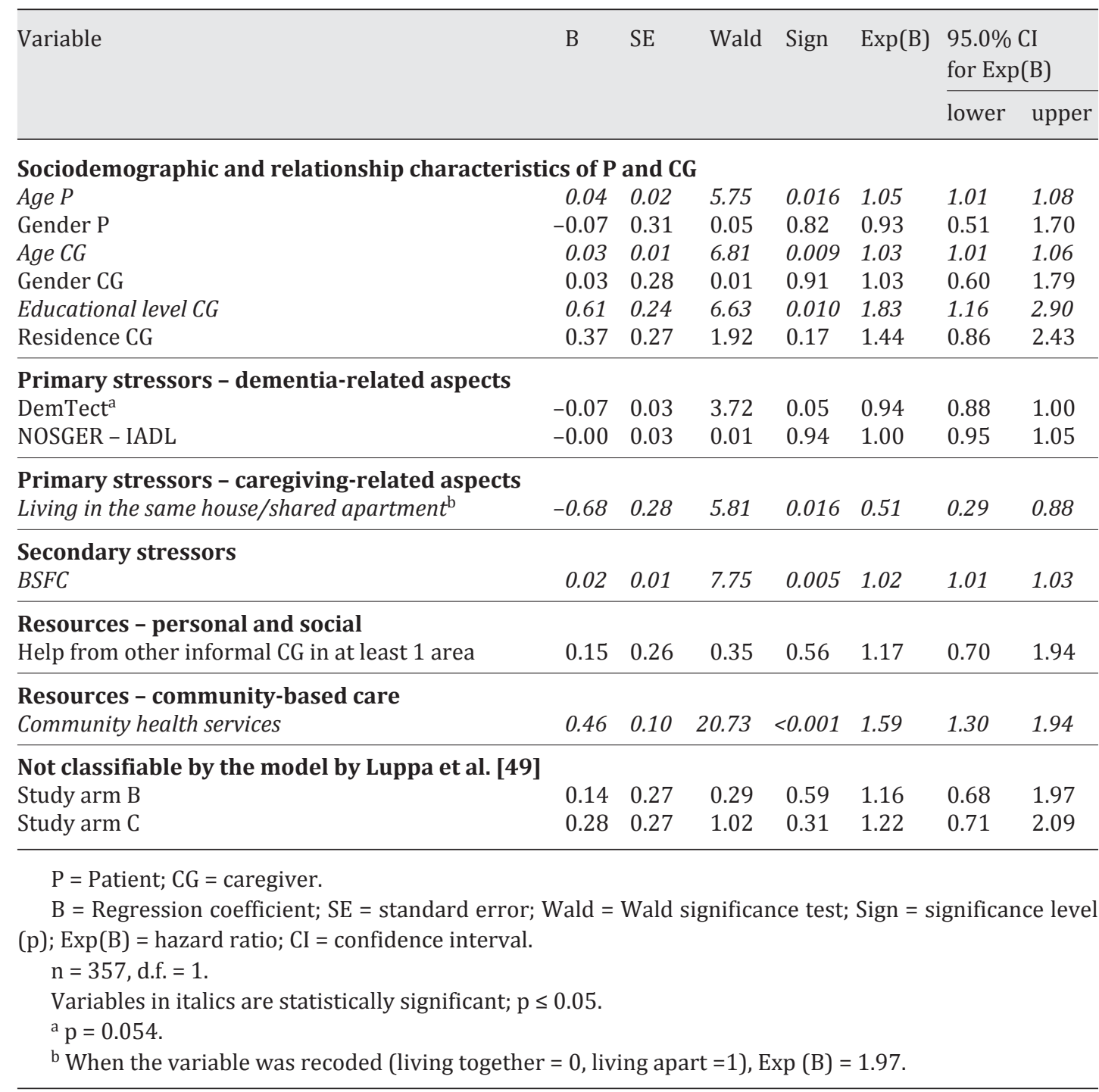

\section{Discussion}

The following characteristics were shown to be significant predictors of institutionalization in the multivariate Cox regression: the dementia patient's and caregiver's age, cohabitation of the patient and caregiver, the educational level of the caregiver, caregiver burden, and the use of community-based health services.

Age

Both age variables were found to be stable predictors of institutionalization, even if they were no longer treated as adjustment variables. In order to determine how the predictive effect of the variable 'age' could be explained, we performed further multivariate analyses for the caregiver groups 'spouse' and 'non-spouse'. For the non-spouse group (mainly children or children-in-law), the caregiver's age remained a significant predictor of institutionalization $(p=0.013)$, but the patient's age did not $(p=0.23)$. This means that the children/children-inlaw, in particular, cared for the patient at home, regardless of how old the patient was. Only 
Eska et al.: Predictors of Institutionalization of Dementia Patients in Mild and Moderate Stages: A 4-Year Prospective Analysis

the caregiver's age seemed to determine institutionalization of the patient: the older the caregiver, the more likely became institutionalization. We found no moderate or strong correlation between the non-spouse's age and other variables, not even with self-rated physical health $(\mathrm{r}=-0.20)$. This indicates that the relation between age and institutionalization among non-spouse caregivers was largely independent of a subjective deterioration of physical health with increasing age. What makes older non-spouses willing to institutionalize their demented family members remains a topic for future research.

In the group of caregiving spouses, neither the caregiving spouse's age $(p=0.17)$ nor the patient's age $(p=0.40)$ remained significant. This means that spouses continued to care at home, independent of their own age and independent of the patient's age. Age was thus not decisive for institutionalization; whereby for other (non-spouse) caregivers, only the caregiver's age played a role. This leads to the conclusion that caregiving spouses differ from other informal caregivers. It seems as if caregiving spouses, unlike caregiving children (-in-law), remain relatively uninfluenced by age or age-related aspects. They seem to remain uninfluenced by external conditions and their own needs in their decisions concerning institutionalization $[45,46]$.

\section{Living Situation}

The cohabitation of the patient and caregiver was found to be another significant predictor of institutionalization. In a differentiated analysis, however, this variable was significant only for non-spouse caregivers $(p=0.016)$ and not for caregiving spouses $(p=0.99)$ who lived together in most cases. This group difference may be a result of low variance in the caregiving spouse group. The risk of institutionalization increased for dementia patients who did not live in the same house or apartment with the caregiving children (-in-law). This can be explained, on the one hand, by the greater investment of time and effort necessary to provide care arising from the spatial distance. On the other hand, this may also be explained by the emotional bond which is less pronounced in caregivers and patients who live apart and stronger in caregivers and patients who live together. The separation resulting from institutionalization may be more difficult to cope with for someone who lives together with a demented family member than for someone who is 'used to' the distance in home care.

\section{Educational Level}

With respect to educational level, a higher educational level of the caregiver was found to indicate a significantly higher risk of institutionalization. This can be interpreted as due to the fact that, in the German health care system, payments out of pocket must always be made by patients or their family members for institutional care because only about $50 \%$ of the costs are financed through the nursing care insurance. Those private costs can probably be more easily paid by caregivers with a higher educational level and the attendant better-qualified professions with higher incomes. Other studies, in contrast, have reported no influence of socioeconomic predictors or inconsistent findings [27, 40].

\section{Subjective Caregiver Burden}

Furthermore, a higher subjective burden of the informal caregiver was coupled with a higher risk of institutionalizing the dementia patient. This indicates that the subjective evaluation of the care situation is an important predictor of the desire to institutionalize. The subjective burden has also been found to be a significant mediator [37, 39] or resilience factor [82]. In principle, the subjective burden can be influenced externally and therefore represents an effective starting point for interventions, see for example Etters et al. [83]. 
Eska et al:: Predictors of Institutionalization of Dementia Patients in Mild and Moderate Stages: A 4-Year Prospective Analysis

\section{Use of Community Health Services}

The use of community health services was found to be the strongest predictor in our analysis: the more formal services were used, the higher the risk of institutionalization. The use of community health services can be regarded as part of the process that leads to institutionalization. The use of formal services may possibly be one section of the difficult adaptation process of placing the demented family member in a nursing home. It requires a reorientation, a redefining of roles, and turning the care over to others. By that, the family caregiver successively 'practices' handing over responsibility and partially learns how to 'let the patient go'. Research findings support this hypothesis [44, 84]. Additionally, in 2011 Lloyd and Stirling [85] demonstrated that the use of formal services may also have negative consequences, such as an emotional strain on the family caregiver, which may be an evidence of the (emotional) release process. The results published by Haley et al. [86] also support this hypothesis, such that the caregivers who had institutionalized their spouse experienced a reduction in depressive symptoms, which continued after the patient's death. These findings suggest that the use of formal services may possibly provide an essential preparatory stage for institutionalization and that institutionalization may provide an essential preparatory stage for losing the dementia patient to death.

\section{Incontinence}

Contrary to the findings of previous studies [40, 43, 87, 88], urinary and fecal incontinence did not show a significant association with institutionalization in our study. This leads to the conclusion that the role of many single variables (e.g. incontinence or time required for care) as independent predictors and existing interactions among them have not yet been definitively clarified.

\section{Conceptual Framework}

Luppa et al. [49] presented a model for predicting institutionalization of dementia patients. They combined elements of the predictor models by Anderson [50], Pearlin et al. [51], and Pruchno et al. [52] with a review of empirical studies. The results of our study confirm the significant influence of 6 predictor variables, which statistically independently represent all of the main areas in the model by Luppa et al. [49]. By recording a wide range of variables across various data sources and methods, and by excluding multicollinearity, our data validate the subdivision by Luppa et al. [49] in principle. But not all potential predictors could be integrated into the original model. Figure 1 also contains suggestions for modifications. The model should be expanded by 'psychological aspects' for both caregivers (e.g. caregiver burden) and patients (e.g. the patients' quality of life). In our study, caregiver burden was found to be the second strongest predictor, which confirms that psychological aspects are very important for institutionalization in the area of the need variables $[89,90]$. We suggest an additional expansion of the model by Luppa et al. [49] by adding the area of 'health-related aspects', e.g. for the patient's comorbidities and the caregiver's physical health (see fig. 1). Other studies have found that, in addition to dementia, physical illness is an important predictor of institutionalization, too $[91,92]$. As the caregiver's health may change both due to caregiving and independently of it, it should be assigned not only to caregiving-related aspects, as it is done in the original model. The same applies to the hospitalization of patients and caregivers. Moreover, in the model by Luppa et al. [49], the potential influence of therapeutic measures on institutionalization is not taken into account, e.g. drug and non-drug therapy. There is evidence for the delay of institutionalization due to medication-based treatment [93] and nonpharmacological interventions $[94,95]$. In the same way, drugs affect the predictors themselves and may therefore have an indirect effect on institutionalization $[96,97]$. Finally, the expanded model offers 
Eska et al.: Predictors of Institutionalization of Dementia Patients in Mild and Moderate Stages: A 4-Year Prospective Analysis

the possibility of integrating additional variables from other models, such as 'caregiver's self-esteem' [51], 'number of children of the patient' [52], 'genetic factors', or 'health beliefs' [50].

\section{Strengths and Limitations}

Some of our study's strengths are the large number of cases and the observation period of 4 years. Moreover, the sample did not consist of highly selective patients recruited from specialized inpatient or outpatient facilities, but the patients were recruited via their general practitioners. Furthermore, the study used several data sources with a large number of variables. This enabled extensive analyses of potential predictor variables, on the one hand, and the validation of the model by Luppa et al. [49], on the other. The sensitivity analysis revealed a stable predictor model.

The sample is not representative of all home-dwelling dementia patients in Germany. A reason for that may be the focus on mild or moderate dementia in the primary study. However, other selection biases, as described above, were avoided. Another limitation is that, despite the broad data set, it was not possible to test all variables in the model by Luppa et al. [49]. Additionally, single events, such as hospitalization, may have a special influence on the risk of institutionalization. Such dynamic effects on institutionalization have to be considered in future research.

\section{Conclusion}

Our study shows that institutionalization is determined multifactorially by only a few significant variables, and thus complex prediction models may have been overestimated so far [32]. These variables seem to have diverse influences on different subgroups. It appears reasonable to distinguish in particular between caregiving spouses and non-spouses. Our results provide evidence that interventions intended to postpone institutionalization are more promising for caregiving children (-in-law) than for spouses. Of the 41 variables analyzed, 6 remained significant predictors; only 1 of these (caregiver burden) can really be influenced externally. This means that interventions that reduce the caregiver burden should be in a position to effectively change the institutionalization process $[83,98]$.

\section{Acknowledgements}

The IDA project was initiated and financed by 4 partners with equal rights in its conception, development, and implementation: the Federal Association of the AOK and the AOK Bavaria Health Insurer (one of the largest statutory health insurance companies in Germany), and the research-based pharmaceutical companies Eisai and Pfizer. The authors thank the following members of the IDA working group for their constructive and helpful support: Reiner Leidl (Helmholtz Zentrum Muenchen), Peter Marx (Pfizer), Hilmar Mehlig (Eisai), Petra Menn (Helmholtz Zentrum Muenchen), Martina Sitte (Federal Association of the AOK), and Sonja Wunder (AOK Bavaria-Health Insurer). Furthermore, we acknowledge support by the Deutsche Forschungsgemeinschaft and the Friedrich-Alexander Universität ErlangenNuernberg within the funding program Open Access Publishing. 
Eska et al.: Predictors of Institutionalization of Dementia Patients in Mild and Moderate Stages: A 4-Year Prospective Analysis

\section{Disclosure Statement}

The sponsors have commissioned 2 academic research institutions with the scientific evaluation of the IDA project by providing unconditional research funds. A contract between the sponsors and the academic researchers ensures that the latter have full scientific responsibility and have the right to publish the results. Members of the sponsoring organizations closely cooperate in designing and conducting the project, but only the academic researchers have full access to all the data in this study and take complete responsibility for the integrity of the data and the accuracy of the data analysis.

\section{References}

$>1$ Luppa M, Riedel-Heller SG, Stein J, Leicht H, Koenig HH, van den Bussche H, Maier W, Scherer M, Bickel H, Moesch E, Werle J, Pentzek M, Fuchs A, Eisele M, Jessen F, Tebarth F, Wiese B, Weyerer S: Predictors of institutionalisation in incident dementia - results of the German Study on Ageing, Cognition and Dementia in Primary Care Patients (AgeCoDe study). Dement Geriatr Cogn Disord 2012;33:282-288.

-2 Borup JH, Gallego DT, Heffernan PG: Relocation: its effect on health, functioning and mortality. Gerontologist 1980;20:468-479.

-3 Cheng TW, Chen TF, Yip PK, Hua MS, Yang CC, Chiu MJ: Comparison of behavioral and psychological symptoms of Alzheimer's disease among institution residents and memory clinic outpatients. Int Psychogeriatr 2009;21: 1134-1141.

-4 Seyfried LS, Kales HC, Ignacio RV, Conwell Y, Valenstein M: Predictors of suicide in patients with dementia. Alzheimers Dement 2011;7:567-573.

5 Leung FW, Rao SSC: Fecal incontinence in the elderly. Gastroenterol Clin North Am 2009;38:503-511.

6 Lieberman MA: Institutionalization of the aged: effects on behavior. J Gerontol 1969;24:330-340.

7 Zarit SH, Whitlatch CJ: Institutional placement: phases of the transition. Gerontologist 1992;32:665-672.

-8 Grant I, Adler KA, Patterson TL, Dimsdale JE, Ziegler MG, Irwin MR: Health consequences of Alzheimer's caregiving transitions: effects of placement and bereavement. Psychosom Med 2002;64:477-486.

-9 Gaugler JE, Mittelman MS, Hepburn K, Newcomer R: Clinically significant changes in burden and depression among dementia caregivers following nursing home admission. BMC Med 2010;8:85.

10 Gaugler JE, Pot AM, Zarit SH: Long-term adaptation to institutionalization in dementia caregivers. Gerontologist 2007;47:730-740.

11 von Kaenel R, Mausbach BT, Dimsdale JE, Mills PJ, Patterson TL, Ancoli-Israel S, Ziegler MG, Roepke SK, Chattillion EA, Allison M, Grant I: Cardiometabolic effects in caregivers of nursing home placement and death of their spouse with Alzheimer's disease. J Am Geriatr Soc 2011;59:2037-2044.

12 Schulz R, Belle SH, Czaja SJ, McGinnis KA, Stevens A, Zhang S: Long-term care placement of dementia patients and caregiver health and well-being. JAMA 2004;292:961-967.

$\$ 13$ Lieberman MA, Fisher L: The effects of nursing home placement on family caregivers of patients with Alzheimer's disease. Gerontologist 2001;41:819-826.

14 von Kaenel R, Mausbach BT, Dimsdale JE, Mills PJ, Patterson TL, Ancoli-Israel S, Ziegler MG, Roepke SK, Chattillion EA, Allison M, Grant I: Effect of chronic dementia caregiving and major transitions in the caregiving situation on kidney function: a longitudinal study. Psychosom Med 2012;74:214-220.

15 Yamamoto-Mitani N, Aneshensel CS, Levy-Storms L: Patterns of family visiting with institutionalized elders: the case of dementia. J Gerontol B Psychol Sci Soc Sci 2002;57:S234-S246.

16 Gaugler JE: Family involvement in residential long-term care: a synthesis and critical review. Aging Ment Health 2005;9:105-118.

17 Papastavrou E, Kalokerinou A, Papacostas SS, Tsangari H, Sourtzi P: Caring for a relative with dementia: family caregiver burden. J Adv Nurs 2007;58:446-457.

18 Nikzad-Terhune KA, Anderson KA, Newcomer R, Gaugler JE: Do trajectories of at-home dementia caregiving account for burden after nursing home placement? A growth curve analysis. Soc Work Health Care 2010;49: 734-752.

19 Tew CW, Tan LF, Luo N, Ng WY, Yap P: Why family caregivers choose to institutionalize a loved one with dementia: a Singapore perspective. Dement Geriatr Cogn Disord 2010;30:509-516.

20 Schneekloth U: Trends in help and care needs in private households; in Schneekloth U, Wahl HW (eds): Possibilities and Limitations of Independent Living in Private Households (MuG III) (in German). Munich, Bundesministerium für Familie, Senioren, Frauen und Jugend, 2005, pp 55-98.

21 Dellasega C, Mastrian K: The process and consequences of institutionalizing an elder. West J Nurs Res 1995; 17:123-140. 
22 Chang YP, Kraenzle-Schneider J, Sessanna L: Decisional conflict among Chinese family caregivers regarding nursing home placement of older adults with dementia. J Aging Stud 2011;25:436-444.

23 Schwarzkopf L, Menn P, Kunz S, Holle R, Lauterberg J, Marx P, Mehlig H, Wunder S, Leidl R, Donath C, Graessel E: Costs of care for dementia patients in community setting: an analysis for mild and moderate disease stage. Value Health 2011;14:827-835.

24 Bickel H: Old age dementia: estimates of prevalence and cost. Z Gerontol Geriatr 2001;34:108-115.

25 Gnjidic D, Stanaway FF, Cumming R, Waite L, Blyth F, Naganathan V, Handelsman DJ, Le Couteur DG: Mild cognitive impairment predicts institutionalization among older men: a population-based cohort study. PLoS One 2012;7:1-8.

26 Pasquini M, Leys D, Rousseaux M, Pasquier F, Hénon H: Influence of cognitive impairment on the institutionalisation rate 3 years after a stroke. J Neurol Neurosurg Psychiatry 2007;78:56-59.

27 Luppa M, Luck T, Weyerer S, Koenig HH, Braehler E, Riedel-Heller SG: Prediction of institutionalization in the elderly. A systematic review. Age Ageing 2010;39:31-38.

-28 Andel R, Hyer K, Slack A: Risk factors for nursing home placement in older adults with and without dementia. J Aging Health 2007;19:213-228.

29 Andersson M, Guo X, Boerjesson-Hanson A, Liebetrau M, Oestling S, Skoog I: A population-based study on dementia and stroke in 97 year olds. Age Ageing 2012;41:529-533.

-30 Zekry D, Herrmann FR, Grandjean R, Vitale AM, De Pinho MF, Michel JP, Gold G, Krause KH: Does dementia predict adverse hospitalization outcomes? A prospective study in aged inpatients. Int J Geriatr Psychiatry 2009;24:283-291.

31 Hatoum HT, Thomas SK, Lin SJ, Lane R, Bullock R: Predicting time to nursing home placement based on activities of daily living scores - a modelling analysis using data on Alzheimer's disease patients receiving rivastigmine or donepezil. J Med Econ 2009;12:98-103.

-32 Gaugler JE, Yu F, Krichbaum K, Wyman JF: Predictors of nursing home admission for persons with dementia. Med Care 2009;47:191-198.

33 Spijker A, Wollersheim H, Teerenstra S, Graff M, Adang E, Verbey F, Vernooij-Dassen M: Systematic care for caregivers of patients with dementia: a multicenter, cluster-randomized, controlled trial. Am J Geriatr Psychiatry 2011;19:521-531.

-34 Feldman HH, Pirttila T, Dartigues JF, Everitt B, Van Baelen B, Schwalen S, Kavanagh S: Treatment with galantamine and time to nursing home placement in Alzheimer's disease patients with and without cerebrovascular disease. Int J Geriatr Psychiatry 2009;24:479-488.

-35 Schoenmakers B, Buntinx F, Devroey D, Van Casteren V, De Lepeleire J: The process of definitive institutionalization of community dwelling demented vs non demented elderly: data obtained from a network of sentinel general practitioners. Int J Geriatr Psychiatry 2009;24:523-531.

-36 Gaugler JE, Wall MM, Kane RL, Menk JS, Sarsour K, Johnston JA, Beusching D, Newcomer R: The effects of incident and persistent behavioral problems on change in caregiver burden and nursing home admission of persons with dementia. Med Care 2010;48:875-883.

-37 Gaugler JE, Wall MM, Kane RL, Menk JS, Sarsour K, Johnston JA, Schuh K, Newcomer R: Does caregiver burden mediate the effects of behavioral disturbances on nursing home admission? Am J Geriatr Psychiatry 2011;19: 497-506.

-38 Kunik ME, Snow AL, Davila JA, McNeese T, Steele AB, Balasubramanyam V, Doody R, Schulz PE, Kalavar JS, Walder A, Morgan RO: Consequences of aggressive behavior in patients with dementia. J Neuropsychiatry Clin Neurosci 2010;22:40-47.

39 Okura T, Plassman BL, Steffens DC, Llewellyn DJ, Potter GG, Langa KM: Neuropsychiatric symptoms and the risk of institutionalization and death: the aging, demographics, and memory study. J Am Geriatr Soc 2011;59: 473-481.

40 McCallum J, Simons LA, Simons J, Friedlander Y: Delaying dementia and nursing home placement: the Dubbo study of elderly Australians over a 14-year follow-up. Ann NY Acad Sci 2007;1114:121-129.

41 Cohen-Mansfield J, Wirtz PW: The reasons for nursing home entry in an adult day care population: caregiver reports versus regression results. J Geriatr Psychiatry Neurol 2009;22:274-281.

-42 Saposnik G, Cote R, Rochon PA, Mamdani M, Liu Y, Raptis S, Kapral MK, Black SE: Care and outcomes in patients with ischemic stroke with and without preexisting dementia. Neurology 2011;77:1664-1673.

43 Thom DH, Haan MN, Van den Eeden SK: Medically recognized urinary incontinence and risks of hospitalization, nursing home admission and mortality. Age Ageing 1997;26:367-374.

44 McCann JJ, Hebert LE, Li Y, Wolinsky FD, Gilley DW, Aggarwal NT, Miller JM, Evans DA: The effect of adult day care services on time to nursing home placement in older adults with Alzheimer's disease. Gerontologist 2005; 45:754-763.

\$5 López J, Losada A, Romero-Moreno R, Márquez-González M, Martínez-Martín P: Factors associated with dementia caregivers' preference for institutional care (in Spanish). Neurología 2012;27:83-89.

46 Luck T, Luppa M, Weber S, Matschinger H, Glaesmer H, Koenig HH, Angermeyer MC, Riedel-Heller SG: Time until institutionalization in incident dementia cases - results of the Leipzig Longitudinal Study of the Aged (LEILA 75+). Neuroepidemiology 2008;31:100-108.

47 Van den Bosch K, Geerts J, Willemé P: Long-term care use and socio-economic status in Belgium: a survival analysis using health care insurance data. Arch Public Health 2013;71:1-9. 
48 Luppa M, Luck T, Weyerer S, Koenig HH, Riedel-Heller SG: Gender differences in predictors of nursing home placement in the elderly: a systematic review. Int Psychogeriatr 2009;21:1015-1025.

49 Luppa M, Luck T, Braehler E, Koenig HH, Riedel-Heller SG: Prediction of institutionalisation in dementia. A systematic review. Dement Geriatr Cogn Disord 2008;26:65-78.

50 Andersen RM: Revisiting the behavioral model and access to medical care: does it matter? J Health Soc Behav 1995;36:1-10.

51 Pearlin LI, Mullan JT, Semple SJ, Skaff MM: Caregiving and the stress process: an overview of concepts and their measures. Gerontologist 1990;30:583-594.

52 Pruchno RA, Michaels JE, Potashnik SL: Predictors of institutionalization among Alzheimer disease victims with caregiving spouses. J Gerontol 1990;45:259-266.

53 Holle R, Grässel E, Ruckdaschel S, Wunder S, Mehlig H, Marx P, Pirk O, Butzlaff M, Kunz S, Lauterberg J: Dementia care initiative in primary practice - study protocol of a cluster randomized trial on dementia management in a general practice setting. BMC Health Serv Res 2009;9:91.

54 Grossfeld-Schmitz M, Donath C, Holle R, Lauterberg J, Ruckdäschel S, Mehlig H, Marx P, Wunder S, Grässel E: Counsellors contact dementia caregivers - predictors of utilisation in a longitudinal study. BMC Geriatr 2010;10:24.

55 Menn P, Holle R, Kunz S, Donath C, Lauterberg J, Leidl R, Marx P, Ruckdäschel S, Vollmar HC, Wunder S, Grässel E: Dementia care in the general practice setting: a cluster randomized trial on the effectiveness and cost impact of three management strategies. Value Health 2012;15:851-859.

-56 Donath C, Grässel E, Grossfeld-Schmitz M, Menn P, Lauterberg J, Wunder S, Marx P, Ruckdäschel S, Mehlig H, Holle R: Effects of general practitioner training and family support services on the care of home-dwelling dementia patients - results of a controlled cluster-randomized study. BMC Health Serv Res 2010;10:1-14.

57 Folstein M, Folstein S, McHugh P: 'Mini-Mental State'. A practical method for grading the cognitive state of patients for the clinician. J Psychiatr Res 1975;12:189-198.

58 Kalbe E, Kessler J, Calabrese P, Smith R, Passmore AP, Brand M, Bullock R: DemTect: a new, sensitive cognitive screening test to support the diagnosis of mild cognitive impairment and early dementia. Int J Geriatr Psychiatry 2004;19:136-143.

59 Incalzi R, Capparella O, Gemma A, Landi F, Bruno E, Di Meo F, Carbonin P: The interaction between age and comorbidity contributes to predicting the mortality of geriatric patients in the acute-care hospital. J Intern Med 1997;242:291-298.

60 de Groot V, Beckermann H, Lankhorst G, Bouter L: How to measure comorbidity: a critical review of available methods. J Clin Epidemiol 2003;56:221-229.

61 Schneider LS, Olin JT: Clinical global impressions in Alzheimer's clinical trials. Int Psychogeriatr 1996;8:277288.

62 Brooks R: EuroQol: the current state of play. Health Policy 1996;37:53-72.

63 The EuroQol Group: EuroQol - a new facility for the measurement of health-related quality of life. Health Policy 1990;16:199-208.

64 Greiner W, Claes C, Buschbach J, Graf von der Schulenburg JM: Validating the EQ-5D with time trade off for the German population. Eur J Health Econ 2005;6:124-130.

65 Ankri J, Beaufils B, Novella JL, Moronne I, Guillemin F, Jolly D, Ploton L, Blanchard F: Use of the EQ-5D among patients suffering from dementia. J Clin Epidemiol 2003;56:1055-1063.

66 Coucill W, Stirling B, Bentham P, Buckley A, Laight A: EQ-5D in patients with dementia - an investigation of inter-rater agreement. Med Care 2001;39:760-771.

67 Mahoney FI, Barthel DW: Functional evaluation: the Barthel Index. Md State Med J 1965;14:61-65.

68 Spiegel R, Brunner C, Ermini-Fünfschilling D, Monsch A, Notter M, Puxty J, Tremmel L: A new behavioral assessment scale for geriatric out- and in-patients: the NOSGER (Nurses' Observation Scale for Geriatric Patients). Am J Geriatr Psychiatry 1991;39:339-347.

69 Wahle M, Häller S, Spiegel R: Validation of the NOSGER (Nurses' Observation Scale for Geriatric Patients): reliability and validity of a caregiver rating instrument. Int Psychogeriatr 1996;8:525-547.

70 Wimo A, Nordberg G: Validity and reliability of assessments of time comparisons of direct observations and estimates of time by the use of the resource utilization in dementia (RUD)-instrument. Arch Gerontol Geriatr 2007;44:71-81.

71 Wimo A, Winblad B: Resource utilization in dementia: 'RUD Lite'. Brain Aging 2003;3:48-59.

72 Wimo A, Nordberg G, Jansson W, Graftström M: Assessment of informal services to demented people with the RUD instrument. Int J Geriatr Psychiatry 2000;15:969-971.

73 Wimo A, Wetterholm A, Mastey V, Winblad B: Evaluation of the healthcare resource utilization and caregiver time in anti-dementia drug trials - a quantitative battery; in Wimo A, Jönsson B, Karlson G, Winblad B (eds): Health Economics of Dementia. Chichester, John Wiley \& Sons, 1998, pp 465-499.

74 Neubauer S, Holle R, Grossfeld-Schmitz M, Grässel E: Measurement of informal care in a study with demented patients. Int Psychogeriatr 2008;20:1160-1176.

75 Neubauer S, Holle R, Menn P, Grässel E: A valid instrument for measuring informal care time for people with dementia. Int J Geriatr Psychiatry 2009;24:275-282.

76 Gräsel E, Chiu T, Oliver R: Development and Validation of the Burden Scale for Family Caregivers (BSFC). Toronto, Comprehensive Rehabilitation and Mental Health Services, 2003.

77 Rothgang H: Social insurance for long-term care: an evaluation of the German model. Soc Policy Admin 2010; 44:436-460. 
Eska et al.: Predictors of Institutionalization of Dementia Patients in Mild and Moderate Stages: A 4-Year Prospective Analysis

78 Cox DR: Regression models and life-tables. J R Stat Soc B 1972;34:187-220.

79 Schafer JL, Graham JW: Missing data: our view of the state of the art. Psychol Methods 2002;7:147-177.

-80 Peduzzi P, Concato J, Feinstein AR, Holford TR: Importance of events per independent variable in proportional hazards regression analysis - II. Accuracy and precision of regression estimates. J Clin Epidemiol 1995;48: 1503-1510.

-81 Schneider A, Hommel G, Blettner M: Linear regression analysis - part 14 of a series on evaluation of scientific publications. Dtsch Arztebl Int 2010;107:776-782.

82 Gaugler JE, Kane RL, Newcomer R: Resilience and transitions from dementia caregiving. J Gerontol B Psychol Sci Soc Sci 2007;62:38-44.

83 Etters L, Goodall D, Harrison B: Caregiver burden among dementia patient caregivers: a review of the literature. J Am Acad Nurse Pract 2008;20:423-428.

84 Wimo A, Sjoelund BM, Skoeldunger A, Johansson L, Nordberg G, von Strauss E: Incremental patterns in the amount of informal and formal care among non-demented and demented elderly persons: results from a 3-year follow-up population-based study. Int J Geriatr Psychiatry 2011;26:56-64.

85 Lloyd BT, Stirling C: Ambiguous gain: uncertain benefits of service use for dementia carers. Sociol Health Illn 2011;33:899-913.

86 Haley W, Bergman E, Roth D, McVie T, Gaugler J, Mittelman M: Long-term effects of bereavement and caregiver intervention on dementia caregiver depressive symptoms. Gerontologist 2008;48:732-740.

87 Holroyd-Leduc JM, Mehta KM, Covinsky KE: Urinary incontinence and its association with death, nursing home admission, and functional decline. J Am Geriatr Soc 2004;52:712-718.

-88 Tilvis RS, Hakala SM, Valvanne J, Erkinjuntti T: Urinary incontinence as a predictor of death and institutionalization in a general aged population. Arch Gerontol Geriatr 1995;21:307-315.

-89 Fjelltun AM, Henriksen N, Norberg A, Gilje F, Normann HK: Nurses' and carers' appraisals of workload in care of frail elderly awaiting nursing home placement. Scand J Caring Sci 2009;23:57-66.

90 Brodaty H, Donkin M: Family caregivers of people with dementia. Dialogues Clin Neurosci 2009;11:217-228.

91 Harboun M, Dorenlot P, Cohen N, Steinhagen-Thiessen E, Ankri J: Impact of hip fracture, heart failure and weight loss on the risk of institutionalization of community-dwelling patients with dementia. Int J Geriatr Psychiatry 2008;23:1245-1252.

$\$ 92$ Nihtilae EK, Martikainen PT, Koskinen SV, Reunanen AR, Noro AM, Haekkinen UT: Chronic conditions and the risk of long-term institutionalization among older people. Eur J Public Health 2008;18:77-84.

-93 Lopez OL, Becker JT, Wahed AS, Saxton J, Sweet RA, Wolk DA, Klunk W, DeKosky ST: Long-term effects of the concomitant use of memantine with cholinesterase inhibition in Alzheimer disease. J Neurol Neurosurg Psychiatry 2009;80:600-607.

$\$ 94$ Spijker A, Vernooij-Dassen M, Vasse E, Adang E, Wollersheim H, Grol R, Verhey F: Effectiveness of nonpharmacological interventions in delaying the institutionalization of patients with dementia: a meta-analysis. J Am Geriatr Soc 2008;56:1116-1128.

-95 Olazarán J, Reisberg B, Clare L, Cruz I, Peña-Casanova J, Del Ser T, Woods B, Beck C, Auer S, Lai C, Spector A, Fazio S, Bond J, Kivipelto M, Brodaty H, Rojo JM, Collins H, Teri L, Mittelman M, Orrell M, Feldmann HH, Muñiz R: Nonpharmacological therapies in Alzheimer's disease: a systematic review of efficacy. Dement Geriatr Cogn Disord 2010;30:161-178.

-96 Rodda J, Morgan S, Walker Z: Are cholinesterase inhibitors effective in the management of behavioral and psychological symptoms of dementia in Alzheimer's disease? A systematic review of randomized, placebocontrolled trials of donepezil, rivastigmine and galantamine. Int Psychogeriatr 2009;21:813-824.

$\$ 7$ Takeda A, Loveman E, Clegg A, Kirby J, Picot J, Payne E, Green C: A systematic review of the clinical effectiveness of donepezil, rivastigmine and galantamine on cognition, quality of life and adverse events in Alzheimer's disease. Int J Geriatr Psychiatry 2006;21:17-28.

$\$ 98$ Pinquart M, Sörensen S: Helping caregivers of persons with dementia: which interventions work and how large are their effects? Int Psychogeriatr 2006;18:577-595. 